\title{
30. Anti-Filamin and -Vinculin Antibodies in Sera from Patients with Myasthenia Gravis and Polymyositis
}

\author{
By Takeshi Yamamoto,*),**) Shoei Furukawa,*) Michio NoJima,*) \\ Shoichi Ishiura, *) Takeshi SAto,**) and Hideo Sugita*) \\ (Communicated by Setsuro Ebashi, M. J. A., March 12, 1986)
}

Summary. The activity of anti-filamin ( $F$ ) and anti-vinculin (V) antibodies $(\mathrm{Ab})$ was determined in sera from patients with myasthenia gravis (MG), polymyositis (PM) and Duchenne muscular dystrophy (DMD). Compared with normal controls, activities of both antibodies were significantly $(p<0.005)$ higher in sera from patients with $\mathrm{MG}$ and $\mathrm{PM}$, especially with a marked increase in anti-F $\mathrm{Ab}$ in ocular myasthenia. In sera from patients with DMD, both activities were slightly higher. Filamin and vinculin are known to be enriched at the periphery of the Z-discs and in the postsynaptic structures of the neuromuscular junction in skeletal muscle. This suggests that these autoantibodies may play some role in the pathogenesis of MG and PM.

Introduction. Recently, much data has been accumulated which supports the idea that $M G$ and $P M$ are autoimmune diseases. In these diseases, serum autoantibodies against crude extracts of skeletal muscle were reported to increase. Filamin $(\mathrm{Mw} 240 \mathrm{~K})$ and vinculin $(\mathrm{Mw} 130 \mathrm{~K})$ are actin-binding proteins which are enriched at the periphery of Z-discs in skeletal muscle ${ }^{1) .2}$ ) and in the postsynaptic structures of neuromuscular junctions. ${ }^{3)}$

In the present study, anti- $\mathrm{F}$ and $-\mathrm{V}$ antibody activity was measured in sera from patients with $\mathrm{MG}$ and PM, and the results were compared with those of patients with DMD.

Materials and methods. Filamin and vinculin were prepared from chicken gizzards according to the method described by Feramisco and Burridge.4) Antibodies against these proteins were raised in New Zealand white rabbits by repeated injection with Freund's complete adjuvant.

Antibody activity was determined using an Enzyme-linked Immunoadsorbent Assay (ELISA) system as follows; polystyrene microtiter wells were coated with $100 \mu \mathrm{l}$ of filamin or vinculin $(50 \mu \mathrm{g} / \mathrm{ml})$ for $30 \mathrm{~min}$ at room temperature. The solutions were removed, and the wells were incubated with $250 \mu$ lof $1 \% \mathrm{BSA}$ in $0.1 \mathrm{M}$ Tris- $\mathrm{HCl}, \mathrm{pH} 7.6$ (Buffer A) for 1 hour. The wells were then washed with $0.1 \mathrm{M}$ Tris- $\mathrm{HCl}, \mathrm{pH} 7.6$, and $100 \mu \mathrm{l}$ of serum at $1: 1,000$ dilution in Buffer A was added. The plates were incubated overnight at $4^{\circ} \mathrm{C}$, and $100 \mu \mathrm{l}$ of rabbit antihuman IgG was added. After 1 hour at room temperature, the plates were washed, and $100 \mu \mathrm{l}$ of avidin-biotinyl HRP complex was added. After $30 \mathrm{~min}$, the plates were washed, and $100 \mu \mathrm{l}$ of $0.04 \%$ o-phenylenediamine and $0.03 \% \mathrm{H}_{2} \mathrm{O}_{2}$ was added. Absorbance at $490 \mathrm{~nm}$ was then defined as an arbitrary unit in this paper. Blank wells were coated with Buffer A instead of antigens.

To confirm the cross-reactivity and the specificity of the serum antibodies

*) National Center for Nervous, Mental and Muscular Disorders, 4-1-1 Ogawahigashi-Machi, Kodaira, Tokyo 187.

**) Juntendo University, Faculty of Medicine, Department of Neurology, 2-1-1 Hongo, Bunkyo-ku, Tokyo 112. 
[Vol. 62(B),

against filamin and vinculin, antibody-absorption tests were performed. Serum $(100 \mu \mathrm{l}, 1: 1,000$ dilution) from a patient with a high anti-F Ab activity was incubated with $100 \mu \mathrm{l}$ of 5 to $50 \mu \mathrm{g} / \mathrm{ml}$ of purified filamin and a control study was performed without filamin overnight at $4{ }^{\circ} \mathrm{C}$. After incubation, $100 \mu \mathrm{l}$ of the mixture was applied to a microtiter plate previously coated with filamin $(50 \mu \mathrm{l} / \mathrm{ml})$. Following the procedure described above, the routine ELISA procedure was carried out. Anti-V Ab was also tested in the same manner.

Antibody activity was determined in $28 \mathrm{MG}$ patients, including 5 ocular myasthenia, 15 patients with PM and 20 patients with DMD. Twenty healthy adults served as normal controls.

Results. The activity of each antibody in a patient's serum was completely suppressed by the addition of $30 \mu \mathrm{g} / \mathrm{ml}$ of filamin or vinculin (Fig. 1), indicating that the values obtained using the ELISA system accurately reflected the crossreactivity and specificity of human antibodies with filamin and vinculin purified from chicken gizzards.

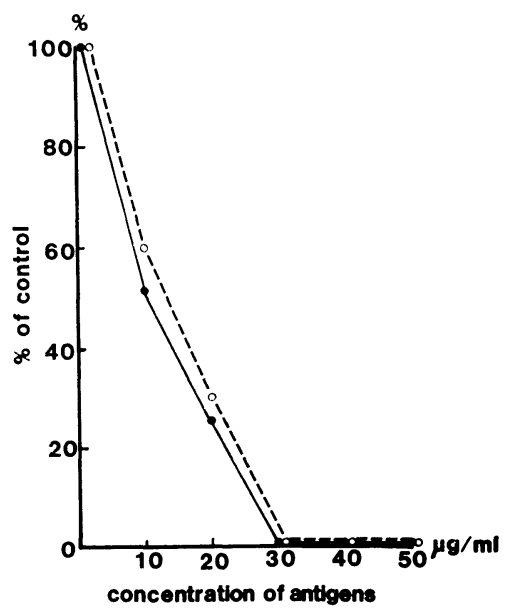

Fig. 1. Antibody-absorption test. Thirty $\mu \mathrm{g} / \mathrm{ml}$ of chicken antigen added to a patient's serum completely suppresses the activity of anti-F $(\bullet)$ and anti-V (O-- $-O)$ $\mathrm{Ab}$ to $0 \%$ of sera without antigens (control).

Antibody activity against chicken gizzard filamin and vinculin in sera from 20 normal controls was $0.10 \pm 0.02$ and $0.66 \pm 0.15$ (mean $\pm \mathrm{SD}$ ), respectively (Figs. 2,3). The upper limit of the normal range was assumed to be the mean +2 SD.

As shown in Fig. 2, 26 out of 28 patients (93\%) with MG showed a significant $(\mathrm{p}<0.005)$ increase in anti-F $\mathrm{Ab}(0.37 \pm 0.16)$. Ocular $\mathrm{MG}$ patients (open circles) showed significantly $(\mathrm{p}<0.01)$ higher values $(0.54 \pm 0.19)$ than those with generalized type $(0.33 \pm 0.13)$. All twelve PM patients showed abnormally high values of anti-F Ab $(0.35 \pm 0.17, \mathrm{p}<0.005)$ compared with 20 normal controls. Thirteen out of 20 patients with DMD $(65 \%)$ also showed a mild but significant increase $(\mathrm{p}<0.005)$ in anti-F Ab activity $(0.16 \pm 0.03)$.

There was a definite increase $(\mathrm{p}<0.005)$ in anti-V Ab values in $50 \%$ of the MG patients $(1.00 \pm 0.27)$ without any clear difference between ocular and gener- 


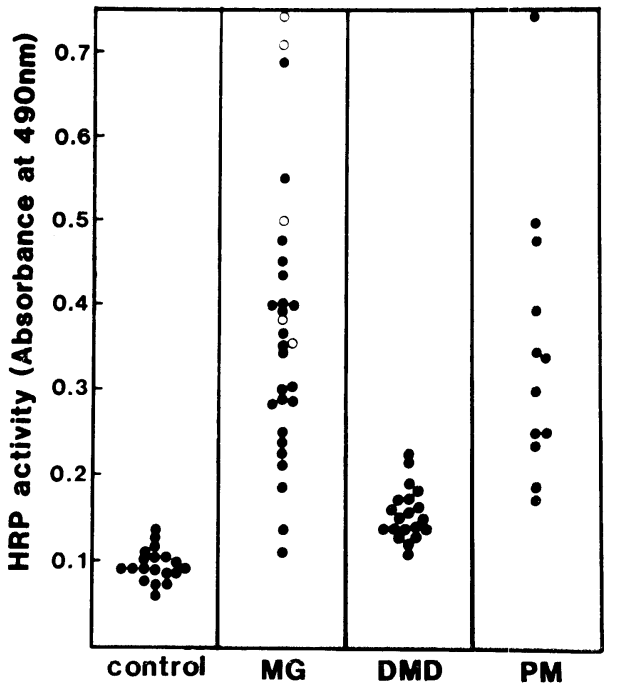

Fig. 2

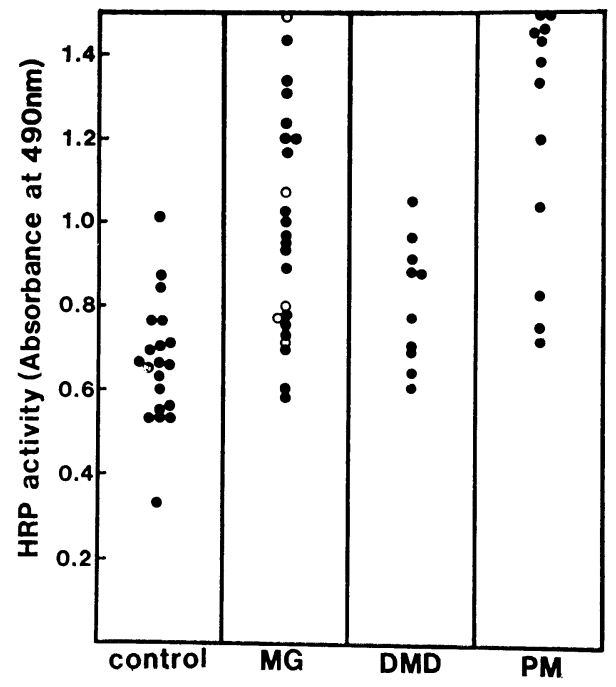

Fig. 3

Figs. 2-3. 2: Activities of anti-filamin antibody. In sera from patients with $\mathrm{MG}$, DMD and PM, activities $(\mathrm{p}<0.005)$ significantly increase compared with normal controls. Note that patients with ocular myasthenia (open circles) show high activities. 3: Activities of anti-vinculin antibody. In sera from patients with $\mathrm{MG}$, DMD and PM, activities increase significantly $(\mathrm{p}<0.005, \mathrm{p}<0.025$ and $\mathrm{p}<0.005$, respectively) compared with normal controls. Open circle=patients with ocular myasthenia.

alized types and $75 \%$ of the PM patients (1.23 \pm 0.32 ) compared with normal controls $(0.66 \pm 0.15)$. Twenty percent of the DMD patients also showed higher activity $(0.81 \pm 0.15, \mathrm{p}<0.025)$ than normal controls (Fig. 3).

Discussion. Several anti-skeletal muscle antibodies not related to the acetylcholine receptor (AchR) are reported to be higher in sera from patients with MG. The antigens used were described as hypertonic sucrose extract," or citric acid (CA) extract ${ }^{(5), \tau}$ ) of the skeletal muscle. These antigens were quite crude and the exact constituents responsible for the antibodies have not yet been clarified.

The present study clearly shows that both anti-F Ab and anti-V $\mathrm{Ab}$ are abnormally higher in sera from MG patients, especially anti-F Ab in ocular MG. Filamin and vinculin have been shown to be localized at the postsynaptic structures and are considered to be components of the cytoskeletal network which support the subsynaptic surface of AchR.3) The remarkably high activity of these autoantibodies in sera from MG patients may be the result of the accelerated destruction of postsynaptic structures due to an increase in anti-AchR Ab. However, the possibility remains that these antibodies play some role in the disruption or conformational change of the AchR.

In $\mathrm{PM}$, high activities of anti-myosin $\mathrm{Ab}^{8}$ ) and anti-myoglobin $\mathrm{Ab}^{9}$ ) have been reported. In this respect, it is interesting to note that the activities of both anti-F and $-\mathrm{V}$ Ab increase in sera from patients with $\mathrm{PM}$, as these proteins are located at the periphery of the $\mathrm{Z}$-discs in skeletal muscle. 
[Vol. $62(\mathrm{~B})$,

The mild increase in both antibodies in DMD is assumed to be nonspecific due to the rapid destruction of the muscle proteins.

Details of this communication will be published elsewhere.

Acknowledgements. The authors wish to express their gratitude to Dr. Hirotake Araki, Director of Sayama Neurology Hospital, for providing some of sera used in this study. This work was supported in part by a Grant-in-aid from the Neuroimmunological Disorders Research Committee, the Ministry of Health and Welfare of Japan, and the Sankyo Foundation of Life Science.

\section{References}

1) Gomer, R. H., and Lazarides, E.: Cell, 23, 524-532 (1981).

2) Shear, C. R., and Bloch, R. J.: J. Cell Biol., 101, 240-256 (1985).

3) Bloch, R. J., and Hall, Z. W.: ibid., 97, 217-223 (1983).

4) Feramisco, J. R., and Burridge, K.: J. Biol. Chem., 255, 1194-1199 (1980).

5) Mehl, V. S., and Lang, R. W.: J. Neuroimmunol., 6, 347-360 (1984).

6) Aarli, J. A. et al.: Europ. Neurol., 20, 380-387 (1981).

7) Gilhus, N. E. et al.: J. Neuroimmunol., 5, 239-249 (1983).

8) Wada K. et al.: Clin. exp. Immunol., 52, 297-304 (1983).

9) Nishikai, M., and Homma, M.: JAMA, 237, 1842-1844 (1977). 